\title{
Commentary on: Laparoscopic Restorative Proctocolectomy Without Diverting Ileostomy
}

\author{
Chucheep Sahakitrungruang ${ }^{*}$ \\ ${ }^{1}$ Department of Surgery, Faculty of Medicine, Chulalongkorn University, Bangkok, Thailand
}

\begin{tabular}{l}
\hline A R T I C L E I N F O \\
\hline Article type: \\
Letter to Editor \\
\hline Article history: \\
Received: 09 Nov 2011 \\
Revised: 20 Nov 2011 \\
Accepted: 26 Nov 2011 \\
\hline Keywords: \\
Laparoscopy \\
Proctocolectomy, Restorative \\
Ileostomy
\end{tabular}

\section{Dear Editor,}

The role of protective ileostomy for restorative proctocolectomy has been debated. Although anastomotic complications can be minimized with protective stoma (1), several authors have reported good outcomes in patients who have undergone restorative proctocolectomy without ileostomy (2-5). A previous report has suggested the possibility of rectal cancer development from the rectal mucosa remnants resulting from ileal pouch-anal anastomosis (IPAA) performed using the stapling technique (6). Therefore, some authors have suggested the selective use of this technique, particularly in patients with familial adenomatous polyposis with rectal sparing; while in other cases, rectal mucosectomy and hand-sewn IPAA have been recommended (7), because the functional or manometric outcome of staple and hand-sewn IPAA is not significantly different $(7,8)$. However, lifelong surveillance of the IPAA is essential in all patients.

The key factor to a successful operation is tension-free anastomosis with good blood supply to the ileal pouch. Therefore, ileal pouch elongation is a crucial step, particu-

\footnotetext{
* Corresponding author: Chucheep Sahakitrungruang, Department of Surgery, Faculty of Medicine, Chulalongkorn University, Bangkok, Thailand. Tel:+6-622564400, Fax:+6-622564194, E-mail: chucheep@hotmail.com
}

- Please cite this paper as:

Sahakitrungruang C. Commentary on: Laparoscopic Restorative Proctocolectomy Without Diverting Ileostomy. J Minim Invasive Surg Sci. 2012;1(1):38-9.

larly in patients with hand-sewn IPAA, where an additional ileal length of 3-4 cm may be required. Several techniques for ileal pouch elongation have been reported, e.g., selective division of branches of the superior mesenteric artery or division of the ileocolic artery. Some authors have advocated preserving the middle colic artery as an additional blood supply route (9). We have proposed the technique of dividing the submesenteric arcades and preserving 3 or 4 of the innermost arcades of the distal ileum as well as both the

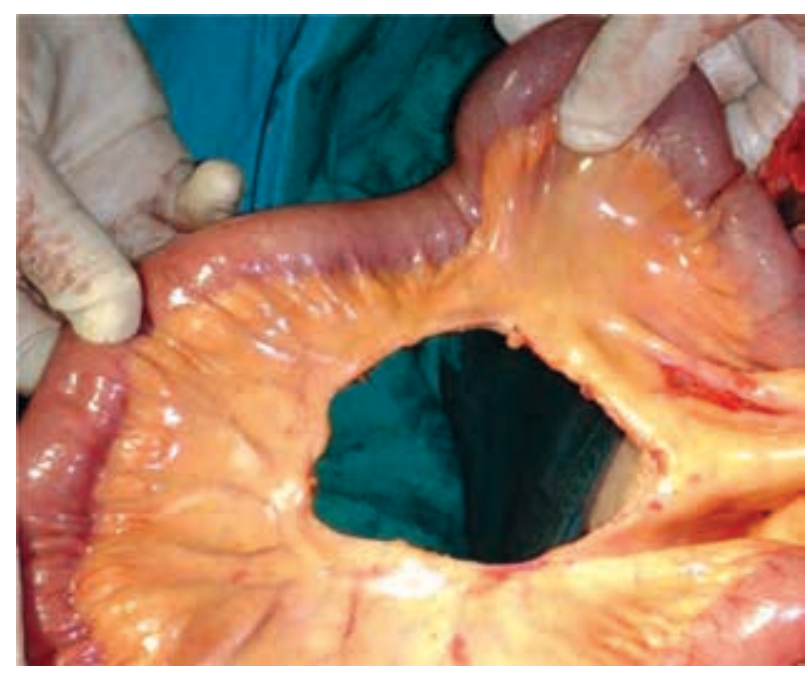

Figure. Ileal pouch elongation by dividing the submesenteric arcades 
superior mesenteric and ileocolic trunks (Figure). This procedure can be easily performed using laparoscopic surgery via a small wound opening and ensures safety during handsewn IPAA without protective ileostomy (10).

\section{Financial Disclosure}

None declared.

\section{References}

1. Koruda MJ. Diverting ostomy with pouch procedure: "causes more morbidity than it prevents!". J Gastrointest Surg. 2009;13(3):401-2.

2. Parks AG, Nicholls RJ. Proctocolectomy without ileostomy for ulcerative colitis. Br Med J.1978;2(6130):85-8.

3. Ryan DP, Doody DP. Restorative proctocolectomy with and without protective ileostomy in a pediatric population.J Pediatr Surg. 2011;46(1):200-3.

4. Sahakitrungruang C, Kanjanasilp P, Pattana-Arun J, Tantiphlachiva K, Rojanasakul A. Outcome of familial adenomatous polyposis: a retrospective study. J Med Assoc Thai. 2006;89(Suppl 3):S155-60.

5. Bananzadeh A, Rezaianzadeh A, Ghahramani L, Hosseini SV.
Laparoscopic Restorative Proctocolectomy Without Diverting Loop Iliostomy in Patients With Familial Adenomatus Polyposis. J Minim Invasive Surg Sci. 2012;1(1):21-3.

6. Ooi BS, Remzi FH, Gramlich T, Church JM, Preen M, Fazio VW. Anal transitional zone cancer after restorative proctocolectomy and ileoanal anastomosis in familial adenomatous polyposis: report of two cases. Dis Colon Rectum. 2003;46(10):1418-23; discussion 22-3.

7. Lovegrove RE, Constantinides VA, Heriot AG, Athanasiou T, Darzi A, Remzi FH, et al. A comparison of hand-sewn versus stapled ileal pouch anal anastomosis (IPAA) following proctocolectomy: a meta-analysis of 4183 patients. Ann Surg. 2006;244(1):18-26.

8. Schluender SJ, Mei L, Yang H, Fleshner PR. Can a meta-analysis answer the question: is mucosectomy and handsewn or doublestapled anastomosis better in ileal pouch-anal anastomosis? Am Surg. 2006;72(10):912-6.

9. Goes RN, Nguyen P, Huang D, Beart RW, Jr. Lengthening of the mesentery using the marginal vascular arcade of the right colon as the blood supply to the ileal pouch. Dis Colon Rectum. 1995;38(8):893-5.

10. Sahakitrungruang C, Pattana-arun J, Tantiphlachiva K, Atithansakul P, Rojanasakul A. Multimedia article. Laparoscopic restorative proctocolectomy with small McBurney incision for ileal pouch construction without protective ileostomy. Dis Colon Rectum. 2008;51(7):1137-8. 